\title{
Performance based evaluation of an existing continuous reinforced concrete bridge - a case study
}

\author{
Erwin Lim $^{1}$, Dyah Kusumastuti ${ }^{*}{ }^{*}$, Rildova ${ }^{1}$, Mario Asneindra ${ }^{1}$, and Silvester Sandy Mulyadi ${ }^{1}$ \\ ${ }^{1}$ Department of Civil Engineering, Faculty of Civil and Environmental Engineering, Bandung Institute of Technology, \\ West Java, Indonesia
}

\begin{abstract}
A performance-based evaluation was conducted on an eleven-span reinforced concrete bridge located in a high seismicity area. This bridge was designed using SNI 2833:1992 and to be checked using the updated Indonesian seismic hazard map. In addition, a non-linear time history analysis was conducted using eleven pairs of ground motions to evaluate the structural performance of the bridge pier for the anticipated service life. Elastic analysis shows that the existing bridge still satisfies the strength and serviceability requirement despite the increase in seismic demand. Meanwhile, by evaluating the average inelastic longitudinal reinforcement and concrete strain at bridge pier for selected eleven ground motions, this study suggests that the bridge is still "fully operational" and "life safety" when subjected to the lower level (100 year return period) and upper level (1000 year return period) ground motions, respectively.
\end{abstract}

\section{Introduction}

An existing eleven-span reinforced concrete bridge located in a high seismicity area was designed using SNI 2833:1992 [1] and constructed in early 2010. In 2016, SNI 2833 [2] related to the seismic design of the bridge was updated and in 2017, an update on the Indonesian seismic hazard map [3] was published. The bridge seismic design approach is quite different between the 1992 and 2016 versions. Therefore, it is of interest to reevaluate the bridge's structural performance using the latest nonlinear time history analysis as the tool. However, since it is an existing bridge, it would be unfair to adopt the latest design requirement and expect the old structure to meet the performance level set by the new regulation.

Federal Highway Administration [4] categorizes the performance level of an existing bridge based on the anticipated service life, bridge importance, and service life category. The performance is evaluated under two levels of ground motion, i.e. lower level (corresponding to the earthquake with a return period of 100 years) and upper level (corresponding to the earthquake with a return period of 1000 years) as shown in Table 1. Unfortunately, this document does not provide a clear approach on how to quantify the expected performance.

On the other hand, NCHRP Synthesis 440 [5] provides an in-depth discussion and background on performancebased seismic design for bridges. Moreover, it also summarizes quantitatively the acceptance criteria for some performance levels, which are available in various regulations. For instance, Table 2 shows the limit criteria for concrete strain evaluated using several regulations. However, some inadequacy was found in this document.

Table 2 suggests that AASHTO SGS, SCDOT, and Caltrans only evaluate the performance under one level of the earthquake, hence not in line with FHWA. Meanwhile, Priestley et.al., in Table 2, has suggested criteria for two-level of earthquakes, i.e. serviceability and damage levels. However, the magnitude of these earthquakes was not specified. POLA/POLB, which regulates the design of ports, has categorized the performance level into three and the magnitudes of respective earthquakes were also specified. However, the intended service life is for 50 years, not 75 years as in bridges. This problem remains until 2020 when NCHRP 949 [6] was published. This guideline fills the gap of FHWA's previous publication and provides quantitative criteria for two levels of evaluated earthquakes.

This study adopts these two guidelines [4,6] and applies them in the performance-based evaluation of the aforementioned bridge. The piers are modeled using the distributed inelasticity or commonly called as fiber model. This technique discretized the pier cross-section, the main seismic resistance element, into fibers. For each concrete and longitudinal steel reinforcement fiber, the stressstrain curve is then explicitly defined. Using this way, it can also capture implicitly the flexural stress-strain behavior of the section along the length through the integration process by assuming plane sections remain plane. Since the length to depth ratio of all piers is larger than 4 where shear behavior is less dominant, this approach is considered appropriate. Although one of the

*Corresponding author: dkusumastuti@gmail.com 
drawbacks of this technique is that it cannot capture the degradation behavior, however considering that all piers satisfy the shear capacity design criteria (will be explained later), the degradation behavior may not be significant as it is controlled by the flexural response.
The performance level is then evaluated using nonlinear time history analysis under eleven pairs of ground motions. Using the average strain value obtained from eleven pairs of ground motions [7], the target performance is evaluated using the NCHRP 949 criteria as shown in Table 3

Table 1. Performance level [4]

\begin{tabular}{|c|c|c|c|c|c|c|}
\hline \multirow[t]{3}{*}{$\begin{array}{l}\text { EARTHQUAKE } \\
\text { GROUND MOTION }\end{array}$} & \multicolumn{6}{|c|}{$\begin{array}{l}\text { BRIDGE IMPORTANCE } \\
\text { and } \\
\text { SERVICE LIFE CATEGORY }\end{array}$} \\
\hline & \multicolumn{3}{|c|}{ Standard } & \multicolumn{3}{|c|}{ Essential } \\
\hline & ASL 1 & ASL 2 & ASL 3 & ASL 1 & ASL 2 & ASL 3 \\
\hline $\begin{array}{l}\text { Lower Level } \\
\text { Ground Motion } \\
50 \text { percent probability of } \\
\text { exceedance in } 75 \text { years; } \\
\text { return period is about } 100 \\
\text { years. }\end{array}$ & PL $0^{4}$ & PL3 & PL3 & PL $0^{4}$ & PL3 & PL3 \\
\hline $\begin{array}{l}\text { Upper Level } \\
\text { Ground Motion } \\
7 \text { percent probability of } \\
\text { exceedance in } 75 \text { years; } \\
\text { return period is about } 1,000 \\
\text { years. }\end{array}$ & PL $0^{4}$ & PL1 & PL1 & PL $0^{4}$ & PL1 & PL2 \\
\hline \multicolumn{7}{|c|}{$\begin{array}{l}\text { Notes: } \\
\text { 1. Anticipated Service Life categories are: } \\
\text { - ASL 1: } 0-15 \text { years } \\
\text { - ASL 2: } 16-50 \text { years } \\
\text { 2. Performance Levels are: } \\
\text { - PL0: No minimum level of performance is recommended. } \\
\text { PL1: Life safety. Significant damage is sustained and service is significantly disrupted, but } \\
\text { life safety is preserved. The bridge may need to be replaced after a large earthquake. } \\
\text { PL2: Operational. Damage sustained is minimal and service for emergency vehicles } \\
\text { should be available after inspection and clearance of debris. Bridge should be reparable } \\
\text { with or without restrictions on traffic flow. } \\
\text { PL3: Fully Operational. No damage is sustained and full service is available for all } \\
\text { vehicles immediately after the earthquake. No repairs are required. } \\
\text { 3. Spectral ordinates and peak ground accelerations may be found as described in Chapter } 2 . \\
\text { 4. Bridges assigned a Performance Level of PLO have } 15 \text { years, or less, anticipated service life } \\
\text { (ASL) and are candidates for replacement or rehabilitation. If the bridge is replaced or } \\
\text { rehabilitated, the ASL category will change and so will the required Performance Level. }\end{array}$} \\
\hline
\end{tabular}

Table 2. Compression strain limit [5]

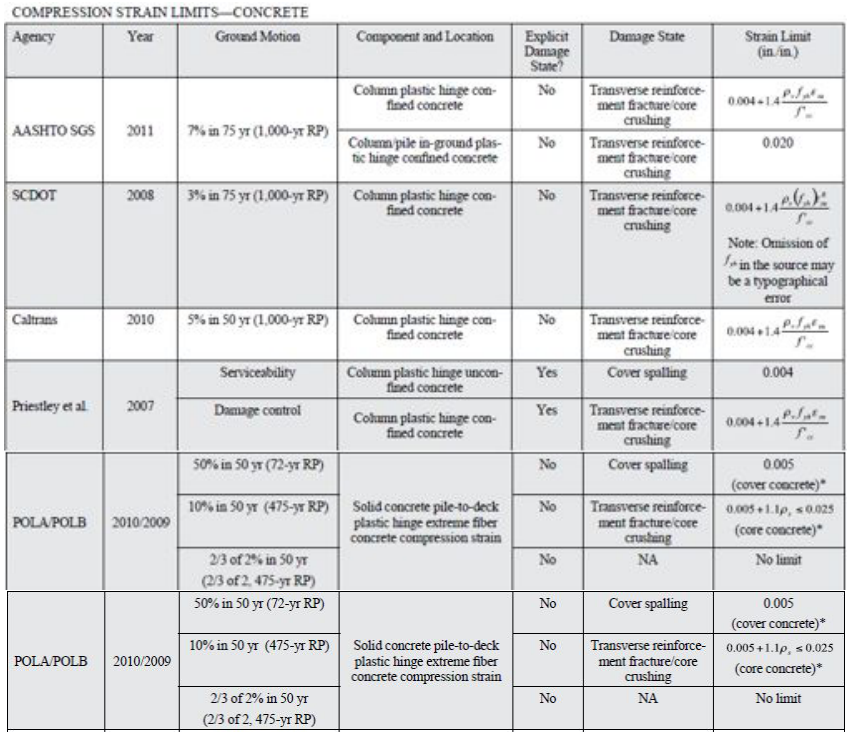

Table 3. Strain limit under targeted performance level [6]

\begin{tabular}{|c|c|c|c|}
\hline \multirow[b]{2}{*}{ Design Parameter } & \multicolumn{3}{|c|}{ Performance Level } \\
\hline & PL1: Life Safety & PL2: Operational & $\begin{array}{l}\text { PL3: Fully } \\
\text { Operational }\end{array}$ \\
\hline $\begin{array}{l}\text { Reinf. tensile strain } \\
\text { limit }\end{array}$ & 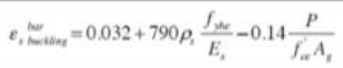 & 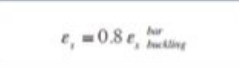 & $\leq 0.010$ \\
\hline $\begin{array}{l}\text { Concrete compressive } \\
\text { strain limit }\end{array}$ & $e_{\epsilon}=1.4\left(0.004+1.4 \frac{\rho_{s} f_{\mu} e_{\mu \mu}}{f_{\epsilon}^{\prime}}\right)$ & 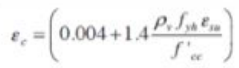 & $\leq 0.004$ \\
\hline
\end{tabular}


Table 3 tabulates the maximum strain of concrete and longitudinal reinforcement bar under three different performance levels predetermined in Table 1. The strain criteria for the reinforcement bar are governed by buckling mode, while that of concrete is limited by the crushing strain of the concrete core.

As an alternative, one can also determine the target performance based on the deformation, instead of strain level. This modeling technique is commonly known as the concentrated hinge model or lumped plasticity. Using this technique, one needs to define the backbone curve representing the force-displacement relationship of the member. Usually, this relationship is represented using a moment-rotation relationship. This relationship will need to incorporate axial and moment interaction. One of the advantages of this technique over distributed plasticity model is that it can capture the strength degradation better. Nevertheless, some assumptions are also needed, such as the determination of plastic hinge length. Also, in the development of the moment-rotation relationship, plane sections remain plane is also used.

\section{Existing Bridge Information}

The bridge under evaluation consists of 11 spans. The first (A1-P1) and last spans (A2-P10) connected to abutments are simply supported, while P1-P6 and P6-P10 spans are continuous as shown in Fig. 1. The typical span length is approximately $42 \mathrm{~m}$, while the pier height varies from $13.5 \mathrm{~m}$ at $\mathrm{P} 1$ to $27 \mathrm{~m}$ at P6. The substructure was assumed to be adequate to resist all loads, and analysis was limited to the upper structures.

The typical transverse section of the bridge is shown in Fig. 2. In the longitudinal direction, the piers behave under single curvature, while in the transverse direction they behave in double curvature. The typical pier dimension is $2 \mathrm{~m} \times 3.5 \mathrm{~m}$, with concrete strength equivalent to $30 \mathrm{MPa}$. The piers' main longitudinal reinforcements are of D25 rebar with steel ratio ranging from $0.7 \%$ to $1.2 \%$ as shown in Fig. 3. Meanwhile, typical hoops and cross ties use D13 rebar.

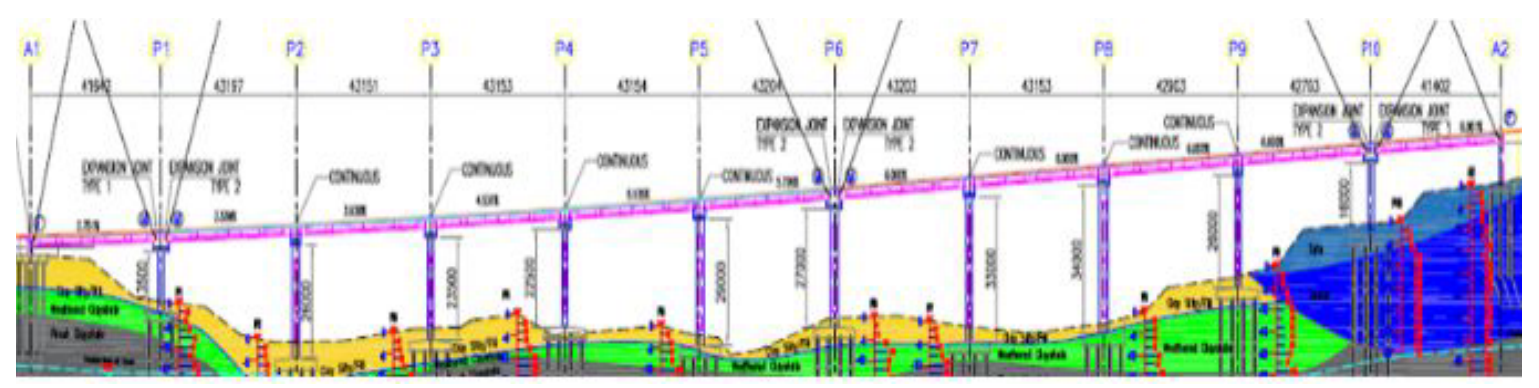

Fig. 1. Longitudinal bridge profil

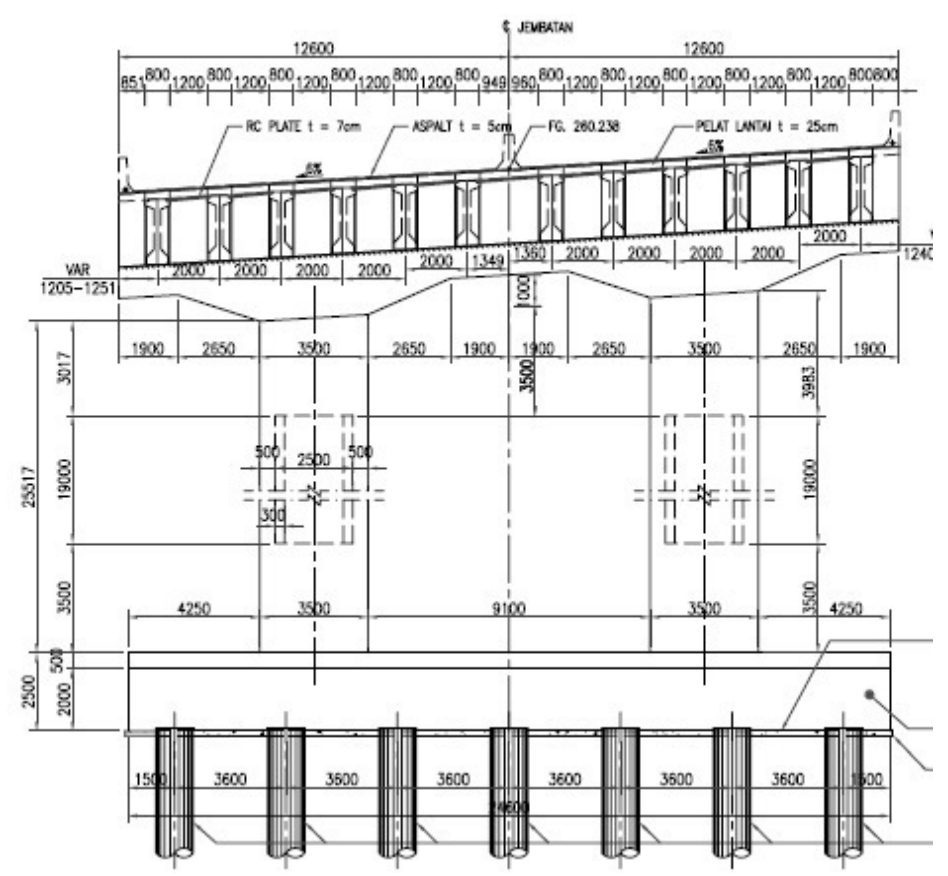

Fig. 2. Transver6se bridge profile 


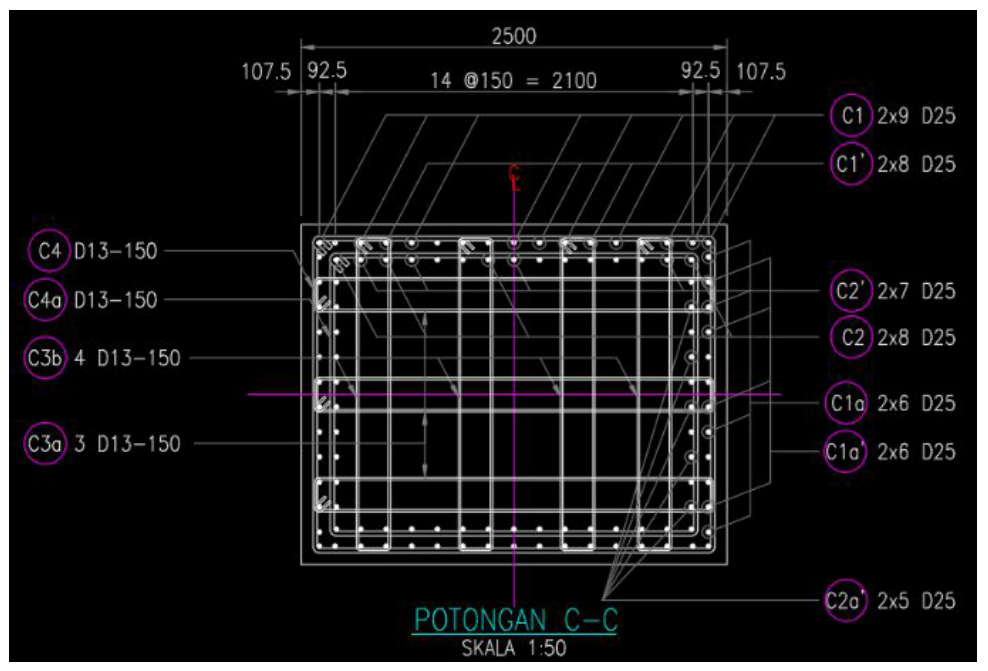

Fig. 3. Typical pier dimension and reinforcement

\section{Elastic Analysis}

The 3D model was developed using the properties specified in the construction drawing and is shown in Fig. 4. Based on dynamic analysis, Table 4 shows dominant mode shapes and the corresponding structural periods. A simple check on the strength adequacy based on the response spectrum in Fig. 5 analysis was carried out. The strength evaluation on piers showed that the flexural capacity of piers was sufficient as shown in the P-M diagram in Fig. 6. Moreover, it was also verified that the piers fulfilled the shear capacity design requirement. In this calculation, the shear strength is compared to the plastic shear demand due to the formation of plastic hinges in piers.

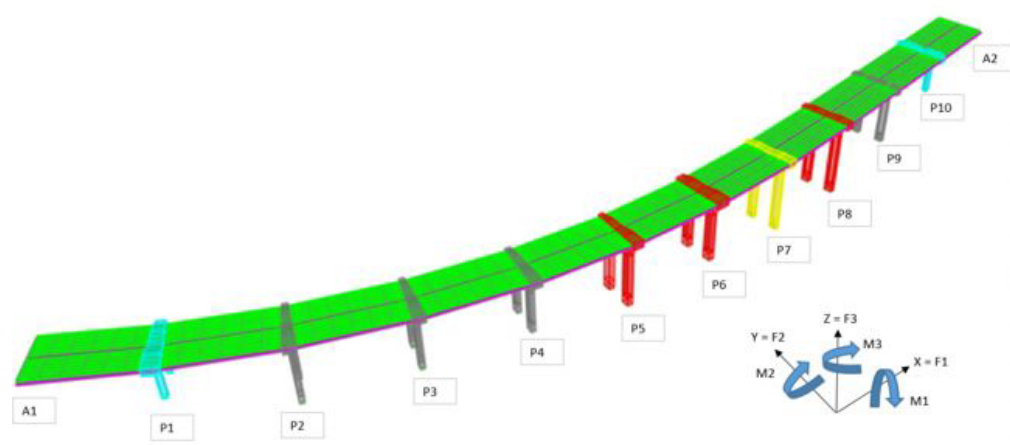

Fig. 4. Three-dimensional modeling

Table 4. Dominant mode shapes

\begin{tabular}{|c|r|r|r|r|r|r|r|}
\hline Mode & \multicolumn{1}{c|}{ Period } & \multicolumn{1}{c|}{ UX } & \multicolumn{1}{c|}{ UY } & SumUX & SumUY & \multicolumn{1}{c|}{ RZ } & \multicolumn{1}{c|}{ SumRZ } \\
\hline Unitless & \multicolumn{1}{c|}{ Sec } & \multicolumn{1}{c|}{ Unitless } & \multicolumn{1}{c|}{ Unitless } & Unitless & Unitless & \multicolumn{1}{c|}{ Unitless } & Unitless \\
\hline 1 & 0.820076 & 0.002544 & 0.43 & 0.002544 & 0.43 & 0.18 & 0.18 \\
\hline 2 & 0.652082 & 0.12 & 0.2 & 0.13 & 0.63 & 0.22 & 0.4 \\
\hline 3 & 0.532955 & 0.07068 & 0.08901 & 0.2 & 0.72 & 0.0001004 & 0.4 \\
\hline 4 & 0.388691 & 0.04942 & 0.008963 & 0.25 & 0.73 & 0.14 & 0.54 \\
\hline 5 & 0.378309 & 0.0003879 & 0.000001451 & 0.25 & 0.73 & 0.001505 & 0.54 \\
\hline 6 & 0.37454 & 0.000001373 & $2.675 \mathrm{E}-07$ & 0.25 & 0.73 & 0.000005156 & 0.54 \\
\hline 7 & 0.356172 & 0.0008917 & 0.00004187 & 0.25 & 0.73 & 0.0002579 & 0.54 \\
\hline 8 & 0.354159 & 0.0001242 & 0.000009287 & 0.25 & 0.73 & 0.0001441 & 0.54 \\
\hline 9 & 0.353168 & 0.0006037 & 0.0003479 & 0.25 & 0.73 & 0.00001141 & 0.54 \\
\hline 10 & 0.352934 & 0.0005314 & 0.0001004 & 0.25 & 0.73 & 0.0000634 & 0.54 \\
\hline 11 & 0.335235 & 0.29 & 0.02299 & 0.54 & 0.75 & 0.06553 & 0.61 \\
\hline 12 & 0.331133 & 0.23 & 0.01642 & 0.77 & 0.77 & 0.05516 & 0.66 \\
\hline 13 & 0.327074 & 0.02939 & 0.002572 & 0.8 & 0.77 & 0.008352 & 0.67 \\
\hline 14 & 0.307504 & 0.00001512 & 0.00008703 & 0.8 & 0.77 & 0.00002483 & 0.67 \\
\hline 15 & 0.304865 & $1.074 \mathrm{E}-09$ & $1.339 \mathrm{E}-08$ & 0.8 & 0.77 & $2.711 \mathrm{E}-09$ & 0.67 \\
\hline 16 & 0.294102 & 0.004307 & 0.05487 & 0.81 & 0.83 & 0.00141 & 0.67 \\
\hline 17 & 0.282639 & 0.0006906 & 0.009036 & 0.81 & 0.83 & 0.0003908 & 0.67 \\
\hline 18 & 0.278257 & 0.00005826 & 0.0000103 & 0.81 & 0.83 & 0.000003453 & 0.67 \\
\hline 19 & 0.27546 & 0.000001118 & 0.000301 & 0.81 & 0.83 & 0.0001221 & 0.67 \\
\hline 20 & 0.27527 & $8.793 \mathrm{E}-07$ & 0.0004812 & 0.81 & 0.84 & 0.00001895 & 0.67 \\
\hline 21 & 0.273059 & 0.00003826 & 0.000001094 & 0.81 & 0.84 & 0.000009663 & 0.67 \\
\hline 22 & 0.256783 & 0.0001183 & 0.00003244 & 0.81 & 0.84 & 0.00003284 & 0.67 \\
\hline 23 & 0.239781 & 0.00005469 & $4.178 \mathrm{E}-07$ & 0.81 & 0.84 & 0.0005385 & 0.67 \\
\hline 24 & 0.237632 & 0.000002316 & 0.000007022 & 0.81 & 0.84 & 0.0003904 & 0.67 \\
\hline 25 & 0.235973 & 0.000008949 & 0.000002656 & 0.81 & 0.84 & 0.0001179 & 0.67 \\
\hline
\end{tabular}


The inspection on shear strength is very important because using the nonlinear time history analysis, only flexural behavior can be modeled and captured. Therefore, by ensuring the shear capacity is adequate, it can be inferred that the flexural behavior of piers can be fully developed and strength degradation due to shear behavior can be delayed. In addition, this check is also important because the pier is analyzed using distributed inelasticity model which cannot capture the degradation behavior well.

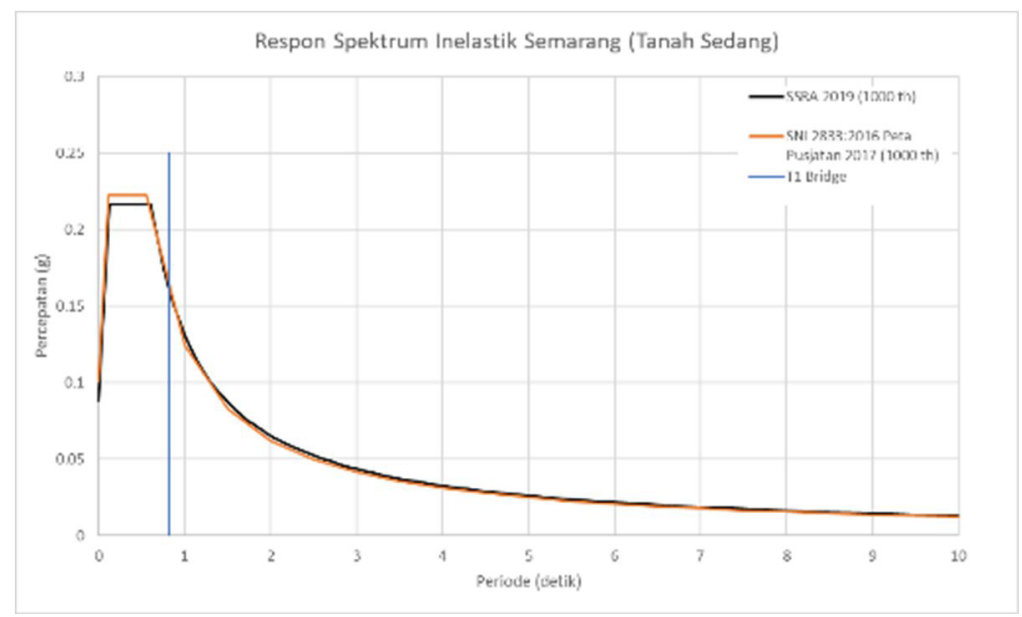

Fig. 5. Inelastic response spectrum

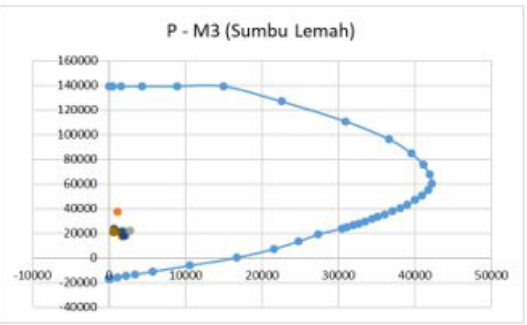

Fig. 6. Typical PM Diagram for piers

\section{Non-Linear Time History Analysis}

As mentioned in NCHRP 949, the criteria of performance level under two levels of an earthquake are evaluated using the strain value, both in piers' extreme concrete fiber and in longitudinal reinforcement bars. Therefore, the fiber model was generated using commercial software and is presented in Fig. 7. First, the pier section was modeled and the concrete material was discretized into 9x9 elements. The longitudinal reinforcements were modeled individually, as indicated in Fig. 7

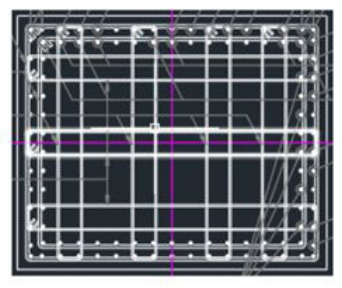

a. Pier section

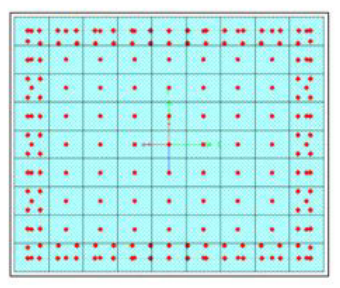

b. Section discretization
Fig. 7. Discretization of pier cross-section

The material constitutive equations for confined concrete and longitudinal steel reinforcement under monotonic loading followed those shown in Fig. 8. The

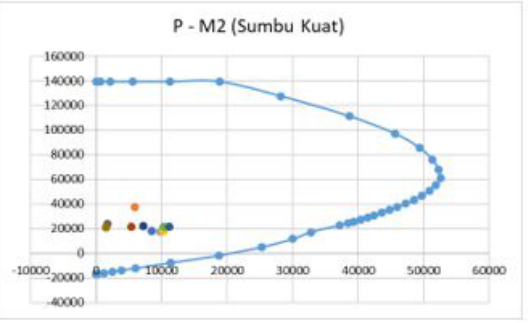

monotonic relationships were then transformed into hysteretic relationships. For concrete material, the Takeda model was adopted, while the kinematic model was used for the reinforcement bar.
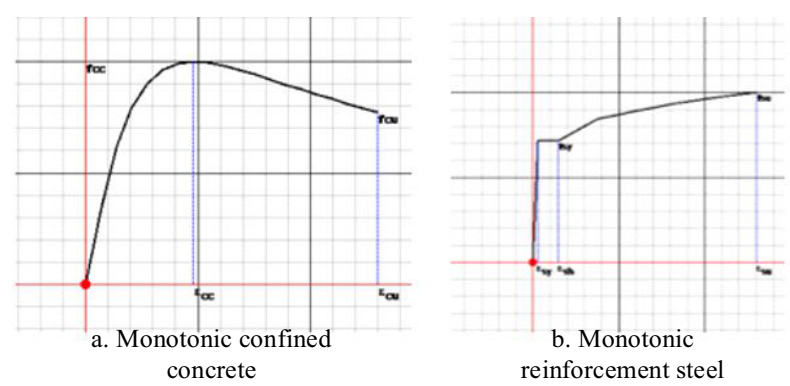

reinforcement steel

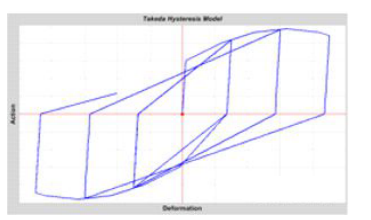

c. Hysteretic confined concrete

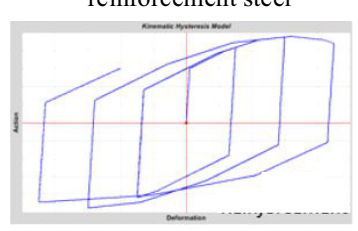

d. Hysteretic steel reinforcement

Fig. 8. Constitutive relationship for material

Eleven pairs of ground motions were developed considering all major earthquake mechanisms within a 
$500 \mathrm{~km}$ radius from the site [8], as shown in Table 5. Figure 9 also plots the acceleration histories for these ground motions. It is noteworthy to mention that two levels of the earthquake [4,6] were developed, i.e., for 100 years return period (lower level) and 1000 years return period (upper level).

After conducting nonlinear time history analyses using eleven pairs of ground motions, the stress and strain histories of extreme concrete fibers and longitudinal reinforcement bars were plotted and examined. An example of the plot is given in Fig. 10. For evaluation on the acceptance criteria, the average of the maximum value obtained for each pair of ground motions is calculated at extreme fibers. These values are then compared with the NCHRP 949's criteria shown in Table 3.

The so-called engineering design parameters values shown in Table 3 links the analysis results to decide the performance level. At the life safety level, the reinforcement strain limit of the longitudinal bar is based on its tensile limit to prevent bar fracture. Meanwhile, the concrete compressive strain limit is based on Mander's model with factor 1.4 to account for the inherited conservatism [6]. For the operational level, the tensile steel strain limit is based on statistical data, in which less than $10 \%$ of rebars are expected to buckle [9], while the concrete compression limit is based on the work of Mander [6]

Table 5. Summary of ground motions

\begin{tabular}{|c|c|c|c|c|c|c|c|}
\hline \multirow{2}{*}{ No } & \multirow{2}{*}{ Ground Motion } & \multirow{2}{*}{ Time (second) } & \multirow{2}{*}{ Direction } & \multicolumn{2}{|c|}{100 years $\mathrm{rp}$} & \multicolumn{2}{|c|}{1000 years rp } \\
\hline & & & & Min Acc. (g) & Max Acc. (g) & Min Acc. (g) & Max Acc. (g) \\
\hline \multirow{2}{*}{1} & \multirow{2}{*}{ Shallow Crustal A-GRN } & \multirow{2}{*}{19.995} & A-GRN180 & -0.2122 & \begin{tabular}{|l|}
0.1585 \\
\end{tabular} & -0.4213 & 0.3375 \\
\hline & & & A-GRN270 & -0.1190 & 0.1562 & -0.2203 & 0.3045 \\
\hline \multirow{2}{*}{2} & \multirow{2}{*}{ Shallow Background FDS } & \multirow{2}{*}{39.98} & FDS262 & -0.1936 & 0.1452 & -0.3670 & 0.2644 \\
\hline & & & FDS172 & -0.1715 & 0.1269 & -0.3383 & 0.2953 \\
\hline \multirow{2}{*}{3} & \multirow{2}{*}{ Benioff Padang30sept } & \multirow{2}{*}{100} & Padang30sept2009EW & -0.0283 & 0.0492 & -0.0620 & 0.0939 \\
\hline & & & Padang30sept2009NS & -0.2156 & 0.2823 & -0.5471 & 0.4786 \\
\hline \multirow{2}{*}{4} & \multirow{2}{*}{ Shallow Crustal A-HMC } & \multirow{2}{*}{17.995} & A-HMC180 & -0.1145 & 0.1078 & -0.2406 & 0.2176 \\
\hline & & & A-HMC270 & -0.1458 & 0.2349 & -0.2703 & 0.4578 \\
\hline \multirow{2}{*}{5} & \multirow{2}{*}{ Shallow Background H-VC4 } & \multirow{2}{*}{29.985} & $\mathrm{H}-\mathrm{VC} 4000$ & -0.2052 & 0.1569 & -0.4055 & 0.3031 \\
\hline & & & H-VC4090 & -0.1384 & 0.1592 & -0.2733 & 0.3162 \\
\hline \multirow{2}{*}{6} & \multirow{2}{*}{ Megathrust-HWA026 } & \multirow{2}{*}{89.995} & HWA026-W & -0.1459 & 0.2182 & -0.2884 & 0.4230 \\
\hline & & & HWA026-N & -0.1096 & 0.1473 & -0.2820 & 0.2951 \\
\hline \multirow{2}{*}{7} & \multirow{2}{*}{ Megathrust-MYG 013} & \multirow{2}{*}{299.99} & MYG013110311146EW & -0.1059 & 0.1232 & -0.2050 & 0.2386 \\
\hline & & & MYG013110311146NS & -0.1642 & 0.2446 & -0.3484 & 0.4614 \\
\hline \multirow{2}{*}{8} & \multirow{2}{*}{ Shallow Crustal PKC } & \multirow{2}{*}{39.975} & PKC360 & -0.2051 & 0.1837 & -0.4118 & 0.3631 \\
\hline & & & PKC090 & -0.1594 & 0.1194 & -0.3153 & 0.2408 \\
\hline \multirow{2}{*}{9} & \multirow{2}{*}{ Megathrust-HKD12 } & \multirow{2}{*}{123.99} & HKD1260309260450 EW & -0.1085 & 0.1915 & -0.2335 & 0.3673 \\
\hline & & & HKD1260309260450 NS & -0.0913 & 0.1923 & -0.2017 & 0.3737 \\
\hline 10 & Megathrust-KAU078 & 89.995 & KAU078-W & -0.2277 & 0.1771 & -0.3601 & 0.4430 \\
\hline & & & KAU078-N & -0.0866 & 0.1283 & -0.2567 & 0.2195 \\
\hline 11 & Beninff KSH & 32975 & KSH-T1 & -0.1841 & 0.1481 & -0.3599 & 0.2924 \\
\hline 11 & (1) & ב & KSH-L1 & -0.1874 & 0.1372 & -0.3648 & 0.2603 \\
\hline
\end{tabular}

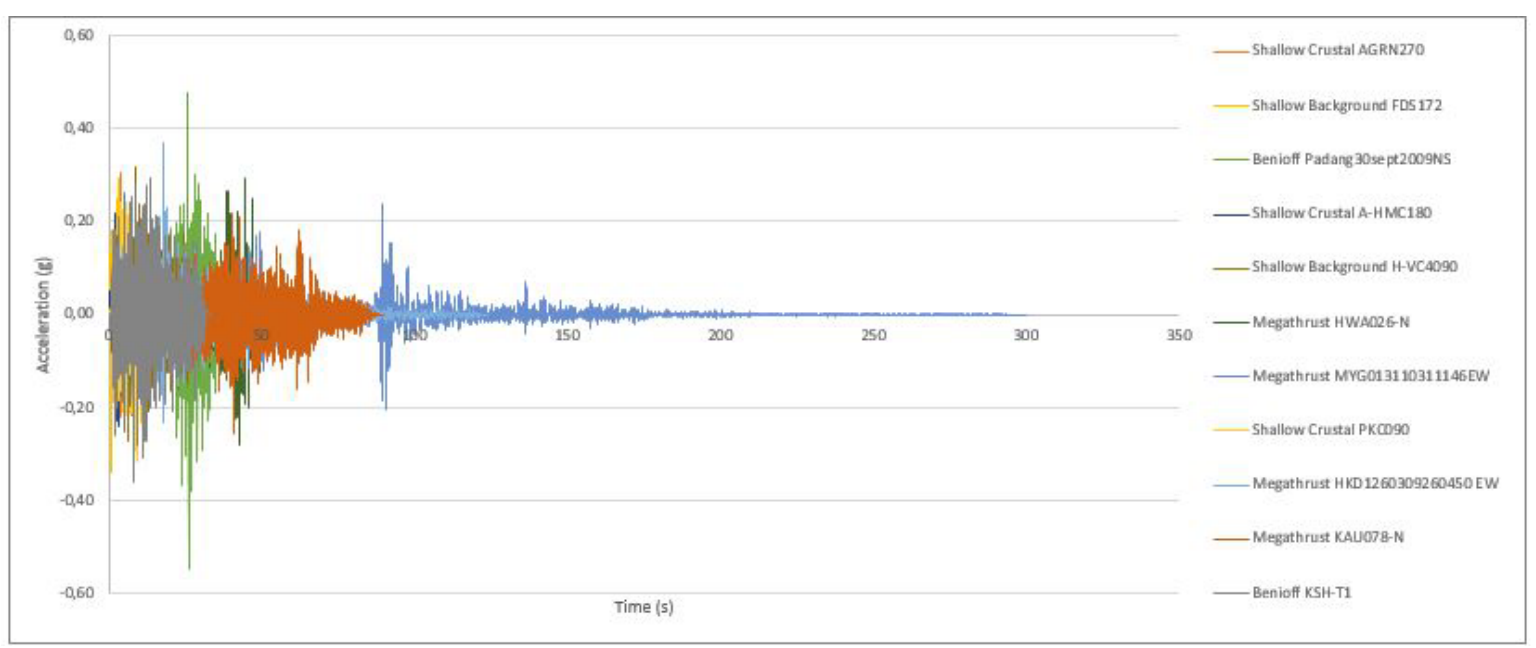

Fig. 9. Acceleration history of 11 ground motion 

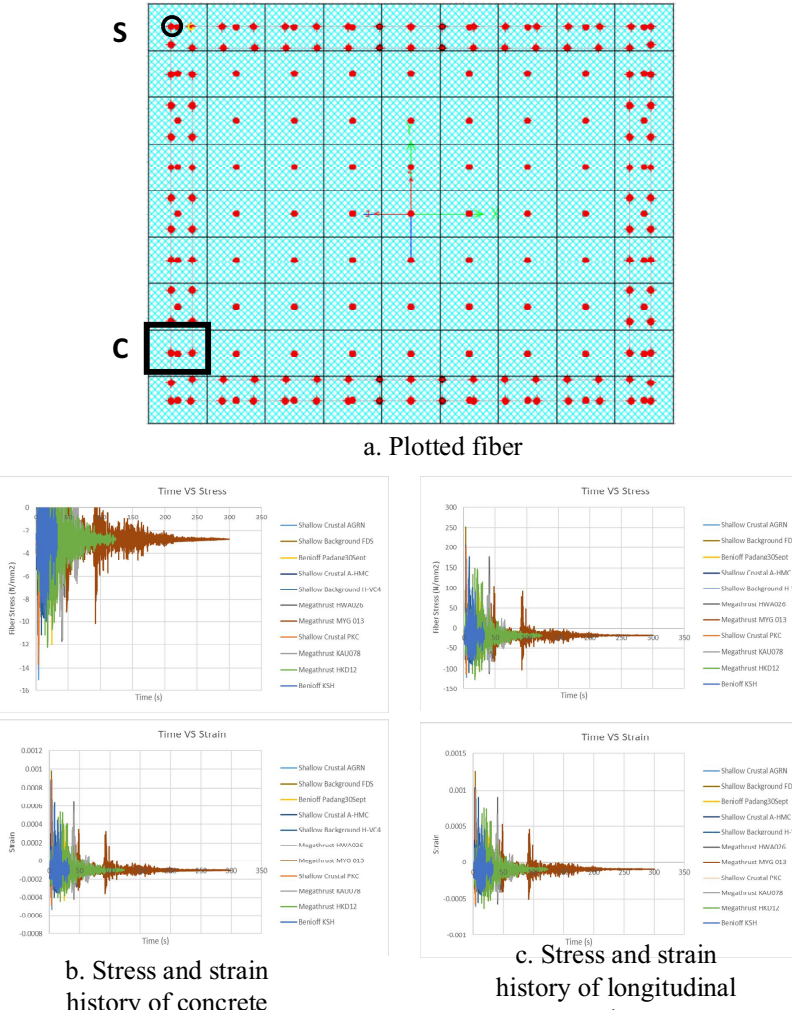

Fig. 10. Stress and strain history for extreme fiber subjected to eleven pairs of ground motio

The comparisons show that for lower-level earthquake ground motion (return period of 100 years), the attained performance level is fully operational, which complies with the FHWA requirement in Table 1. For upper-level earthquake ground motion (return period of 1000 years), the achieved performance level is life safety, which also satisfies the FHWA requirement. Therefore, the existing bridge shows adequate capacity under the current seismic load.

\section{Conclusions}

This study adopts the latest NCHRP 949 Guideline to quantitatively evaluate the performance level of an existing continuous reinforced concrete bridge located in a high seismic zone. This guideline fills the gap of previous guidelines in which the acceptance criteria for strain limit of concrete and longitudinal steel reinforcement under two levels of an earthquake under three different categories, depending on the anticipated service life, are well defined.

The study shows that the guideline can be applied and the results are straightforward in determining the performance level of the bridge. Nonlinear time history analysis using eleven pairs of ground motions generated specifically for the site shows that the performance level of this bridge still satisfies the requirement of FHWA, which is "fully operational" under lower level ground motion earthquakes (return period 100 years) and "life safety" under upper-level ground motion earthquake (return period 1000 years).

The authors wish to thank Prof. I Wayan Sengara, Mr. Det Komardevi, and the team for developing eleven pairs of ground motions at the site under evaluation.

\section{References}

1. National Standardization Agency, SNI 2833-1992, Procedures for Planning Earthquake Resistance for Highway Bridges, BSN, Jakarta (1992)

2. National Standardization Agency, SNI 2833-2016, Earthquake Bridge Planning, BSN, Jakarta (2016)

3. National Standardization Agency, SNI 2833-2016, Earthquake Bridge Planning, BSN, Jakarta (2016)

4. Federal Highway Administration, Seismic retrofitting Manual for Highway Structures, Virginia (2006)

5. National Academies of Sciences, Engineering, and Medicine, NCHRP Synthesis - Performance-Based Seismic Bridge Design, Washington DC, 440 (2013)

6. National Academies of Sciences, Engineering, and Medicine, NCHRP Research Report - Proposed AASHTO Guidelines for Performance-Based Seismic Bridge Design, Washington DC, 949 (2020)

7. National Standardization Agency, SNI 1726-2019, Earthquake Resilience Planning Procedures for Building and Non-Building Structures, BSN, Jakarta (2019)

8. W. Sengara, Det K., personal communication, Bandung (2021)

C. G. Jason, J. K. Mervyn, M. M. James, “ Closure to Modified Plastic-Hinge Method for Circular RC Bridge Columns," J. of. Structural Engineering, 143 (9) (2018). 